\title{
Article \\ Studying Corrosion Using Miniaturized Particle Attached Working Electrodes and the Nafion Membrane
}

\author{
Jiyoung Son ${ }^{1}{ }^{\mathbb{D}}$, Edgar C. Buck ${ }^{1}{ }^{\circledR}$, Shawn L. Riechers ${ }^{1}$, Shalini Tripathi ${ }^{1}$, Lyndi E. Strange ${ }^{1}$, Mark H. Engelhard ${ }^{2}$ \\ and Xiao-Ying $\mathrm{Yu}^{1, * \mathbb{C}}$ \\ 1 Energy and Environment Directorate, Pacific Northwest National Laboratory, Richland, WA 99354, USA; \\ jiyoung.son@pnnl.gov (J.S.); edgar.buck@pnnl.gov (E.C.B.); shawn.riechers@pnnl.gov (S.L.R.); \\ shalini.tripathi@pnnl.gov (S.T.); lyndi.strange@pnnl.gov (L.E.S.) \\ 2 Environmental Molecular Sciences Laboratory, Pacific Northwest National Laboratory, \\ Richland, WA 99354, USA; mark.engelhard@pnnl.gov \\ * Correspondence: xiaoying.yu@pnnl.gov; Tel.: +1-509-372-4524
}

Citation: Son, J.; Buck, E.C.; Riechers, S.L.; Tripathi, S.; Strange, L.E.; Engelhard, M.H.; Yu, X.-Y. Studying Corrosion Using Miniaturized Particle Attached Working Electrodes and the Nafion Membrane.

Micromachines 2021, 12, 1414.

https://doi.org/10.3390/mi12111414

Academic Editor: Aiqun Liu

Received: 22 October 2021

Accepted: 11 November 2021

Published: 18 November 2021

Publisher's Note: MDPI stays neutral with regard to jurisdictional claims in published maps and institutional affiliations.

Copyright: (c) 2021 by the authors. Licensee MDPI, Basel, Switzerland. This article is an open access article distributed under the terms and conditions of the Creative Commons Attribution (CC BY) license (https:// creativecommons.org/licenses/by/ $4.0 /)$.

\begin{abstract}
We developed a new approach to attach particles onto a conductive layer as a working electrode (WE) in a microfluidic electrochemical cell with three electrodes. Nafion, an efficient proton transfer molecule, is used to form a thin protection layer to secure particle electrodes. Spin coating is used to develop a thin and even layer of Nafion membrane. The effects of Nafion (5wt $\% 20 w t \%)$ and spinning rates were evaluated using multiple sets of replicates. The electrochemical performance of various devices was demonstrated. Additionally, the electrochemical performance of the devices is used to select and optimize fabrication conditions. The results show that a higher spinning rate and a lower Nafion concentration $(5 \mathrm{wt} \%)$ induce a better performance, using cerium oxide $\left(\mathrm{CeO}_{2}\right)$ particles as a testing model. The WE surfaces were characterized using atomic force microscopy (AFM), scanning electron microscopy-focused ion beam (SEM-FIB), time-of-flight secondary ion mass spectrometry (ToF-SIMS), and X-ray photoelectron spectroscopy (XPS). The comparison between the pristine and corroded WE surfaces shows that Nafion is redistributed after potential is applied. Our results verify that Nafion membrane offers a reliable means to secure particles onto electrodes. Furthermore, the electrochemical performance is reliable and reproducible. Thus, this approach provides a new way to study more complex and challenging particles, such as uranium oxide, in the future.
\end{abstract}

Keywords: nanoparticle; working electrode; microfluidic electrochemical cell; electrochemical analysis; particle attached electrode; Nafion membrane; System for Analysis at the Liquid-Vacuum Interface (SALVI); $\mathrm{CeO}_{2}$

\section{Introduction}

Cerium dioxide $\left(\mathrm{CeO}_{2}\right)$ adopts a fluorite structure (space group Fm-3m) under ambient conditions, which is common to a variety of dioxides, including uranium oxide $\left(\mathrm{UO}_{2}\right)$, thorium oxide $\left(\mathrm{ThO}_{2}\right)$, plutonium oxide $\left(\mathrm{PuO}_{2}\right)$, and doped zirconium dioxide $\left(\mathrm{ZrO}_{2}\right)$ [1]. Therefore, $\mathrm{CeO}_{2}$ has been used as a surrogate to understand irradiated mixed oxide (MOX)-based matrix fuel due to its similarity in structure and chemical and mechanical properties [2]. For instance, $\mathrm{CeO}_{2}$ was used to study irradiated mixed oxide as irradiated fuel pellet materials in fission reactors due to its similar structural and mechanical properties [3]. $\mathrm{CeO}_{2}$ and $\mathrm{UO}_{2}$ can be engineered to feature similar grain sizes, and $\mathrm{CeO}_{2}$ is often used as an analogue of $\mathrm{UO}_{2}$ in dissolution studies [4]. When considering the safety case for the geological disposal of nuclear waste, $\mathrm{CeO}_{2}$ and $\mathrm{ThO}_{2}$ are effective spent nuclear fuel analogues that approximate the microstructure characteristics of fuel-grade $\mathrm{UO}_{2}$, yet they are not as sensitive to changes in the oxidation state of the cation as uranium [5]. 
Previous efforts utilized millimeter (mm)-sized $\mathrm{UO}_{2}$ spent fuel to reduce the risk of contamination to study the spent fuel corrosion phenomenon [6]. For example, Sunder et al. utilized sliced $\mathrm{UO}_{2}$ pieces that were a few $\mathrm{mm}$ laterally and $3 \mathrm{~mm}$ thick, and they successfully studied $\mathrm{UO}_{2}$ corrosion in an electrolyte containing hydrogen peroxide under open-circuit corrosion conditions [7]. Other previous efforts also used disc type bulk electrodes to achieve results [8-10]. However, such experiments are not easy to conduct; this is largely due to the difficulty of handling highly radioactive materials. Hot cells and other logistics were required to perform such experiments. Therefore, new methods are needed to make such studies more accessible to develop the predictability of spent fuel corrosion potential.

Microfluidics is a viable approach to address the associated technical challenges. Our team developed a microfluidic-based platform for the multimodal spectroscopy and microscopy of liquids [11-13]. This vacuum-compatible platform is named System for Analysis at the Liquid-Vacuum Interface (SALVI). The electrochemical SALVI, or E-cell, contains three electrodes and allows simultaneous electrochemical analysis, which enables multimodal spectroscopy and microscopy including chemical imaging tools such as timeof-flight secondary ion mass spectrometry (ToF-SIMS) and scanning electron microscopy (SEM) [14,15].

We recently introduced a working electrode (WE) fabrication method to include a small amount of nanoparticles in the SALVI cell using stamping [16]. Conductive epoxy was used as a medium for the direct attachment of nanoparticles onto the electrode surface by utilizing several stamping methods. It showed promise for spent fuel corrosion studies using electrochemistry. However, the inconsistency of stamped target particles and the difficulty in controlling the epoxy amount on fabricated WE call for improvement and optimization. A new approach using Nafion, a proton exchange membrane, is developed in this work. Nafion is a perfluorinated polymer with sulfonic acid groups that stands out for its high proton conductivity, its selective permeability to water, and its superior chemical stability [17-19]. Nafion also has been widely used in fuel cells and batteries as the separator and binder materials due to its high proton transfer ability. Specifically, Nafion is used as the barrier membrane material between anodic and cathodic layers in fuel cells $[18,20-22]$. Nafion is used to hold the target particles (i.e., cerium oxide $\mathrm{CeO}_{2}$ ) onto the gold $(\mathrm{Au})$ conductive substrate to form a precisely controlled WE in terms of mass loading and electrode surface area.

In this study, we demonstrate that using micrometer $(\mu \mathrm{m})$-sized electrodes is a novel and alternative solution to study particle corrosion. This is achieved by miniaturizing the working electrode in an established electrochemical cell, that is, the electrochemical version of the SALVI, or the E-cell [11]. The Nafion membrane is used as a protection layer in the E-cell after attaching $\mathrm{CeO}_{2}$ particles. Considering the challenges involved in utilizing $\mathrm{UO}_{2}$, a radioactive chemical, as a WE component with regard to strict safety protocols of radioactive material handling [14,15], its close analogue $\mathrm{CeO}_{2}$ was chosen to develop and optimize the fabrication protocol.

The fabricated $\mathrm{CeO}_{2}$-containing SALVI E-cell devices were tested to show reproducibility and to validate their performance as a new analytical approach. Multimodal surface analysis tools, including time-of-flight secondary ion mass spectrometry (ToF-SIMS), scanning electron microscopy-focused ion beam (SEM-FIB), X-ray photoelectron spectroscopy (XPS), and nanometer resolution atomic force microscopy (AFM) were used to characterize the powder-attached electrode surface to verify the electrically driven corrosion effects on the electrode surface. Microfluidics provides the benefit of singling out the $\alpha$-radiolysis effect due to the small size of the overall electrochemical cell as an inherent feature. The novel microfluidic approach increases the degree of freedom to study more diverse spent fuel corrosion conditions, including synfuels and noble metal particles, in the future. 


\section{Materials and Methods}

\subsection{Chemical Agents}

The Nafion solutions of $5 w t \%$ and $20 w t \%$ were acquired from Sigma Aldrich. The pristine single crystal $\mathrm{CeO}_{2}$ particles were provided by Dr. Dallas Reilly. The cerium oxide $\left(\mathrm{CeO}_{2}, 10 \mathrm{~nm}\right.$ mean diameter) particles were purchased from US Research Materials Inc. (Houston, TX, USA). The polydimethyl siloxane (PDMS) was purchased from Millipore Sigma (Darmstadt, Germany). The silicon (Si) wafer chips (University Wafers, Boston, MA, USA) were used in device development. More details were described previously [16]. The platinum (Pt) wires (25 mm outside diameter) were purchased from Sigma Aldrich (St. Louis, MO, USA).

\subsection{Microfluidic Electrochemical Cell Fabrication}

\subsubsection{WE Fabrication}

A LAURELL 650M spin coater (North Wales, PA, USA) was used to form a thin layer of Nafion with 0,500 and $1000 \mathrm{rpm}$ spinning recipes. The Nafion membrane was used to hold the target particles when making the $\mathrm{WE}$ that contained $\mathrm{CeO}_{2}$ particles. Figure $1 \mathrm{a}$ shows the WE fabrication process using Nafion as the protection membrane. A small amount of target $\mathrm{CeO}_{2}$ particles (e.g., $250 \mathrm{mg}$ ) was suspended in $1 \mathrm{~mL}$ of deionized (DI) water to make a stock with a concentration of $250 \mathrm{mg} / \mathrm{mL}$, as shown in Figure 1a. A few droplets of the particle-suspended liquid mixture were pipetted onto the shadow-masked Au-WE layer on the Si chip [16]. The Si chips were used to reduce the cost of method development. The spun Nafion layer was cured in a $70{ }^{\circ} \mathrm{C}$ oven for another $30 \mathrm{~min}$ to form a homogeneously distributed layer adapted from a protocol in Nafion membrane fabrication $[20,21]$. The Si chips with deposited target particles were dried in the oven at $70{ }^{\circ} \mathrm{C}$ for $30 \mathrm{~min}$. Optical images of each completed WE surface also were recorded with an optical microscope (VHX500, Keyence, Itasca, IL, USA) with a magnification 100 times (see Figure S1). It is worth noting that the optimal amount of particle deposition was investigated by testing many devices in duplicate sets. For example, the initial amount of $\mathrm{CeO}_{2}$ particles was set at $0.6 \mathrm{mg}$. The particle mass loading was increased to show the enhanced effect in the CV testing.

a

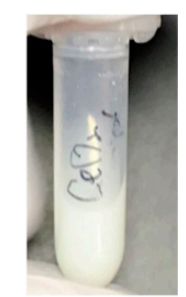

1. Suspend target particles

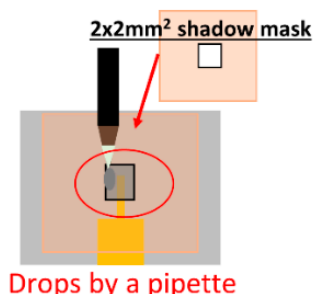

2. Dispense droplets of suspended particles

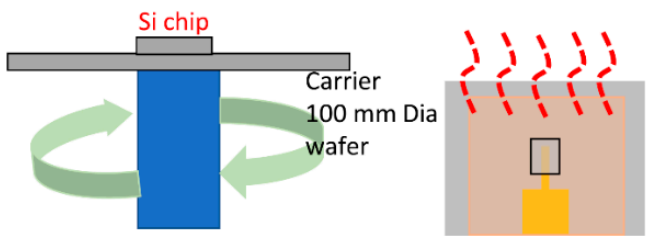

4. Spread the Nafion evenly 5. Cure (oven $70^{\circ} \mathrm{C}$ ) coating using spinner

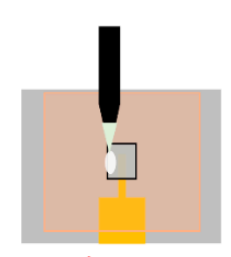

Drop by a pipette

3. Dispense the Nafion solution

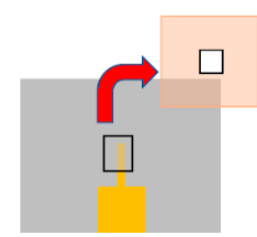

6. Remove the shadow mask

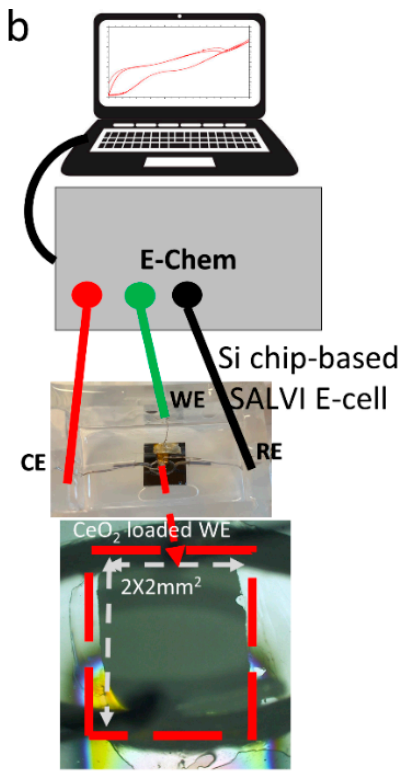

Figure 1. (a) The flow chart of the step-by-step fabrication process of particle deposition (1-3), Nafion film formation (4-5), and the assembled electrochemical device (6); and (b) the setup to perform electrochemical analysis of $\mathrm{CeO}_{2}$ containing SALVI E-cells. 


\subsubsection{Device Assembly}

The SALVI E-cell uses Pt wires as the counter electrode and reference electrode, respectively. The body of the devices was fabricated using soft lithography [23,24]. More details on SALVI fabrication were reported previously [16]. Key details are provided in the Supporting Information.

\subsection{Membrane Thickness Mesurements}

The Nafion membrane thickness was determined using a profilometer (Profilm3D, KLA, Milpitas, CA, USA).

\subsection{Cyclic Voltammetry}

Cyclic voltammetry (CV) was used to verify the microfluidics device performance. The electrolyte containing $0.1 \mathrm{~mol} / \mathrm{L}$ of sodium perchlorate $\left(\mathrm{NaClO}_{4}\right)$ was used following a previous publication using bulk electrodes [7]. A series of $\mathrm{CV}$ potential scans at different scanning rates was performed using multiple E-cells to verify the electrochemical reproducibility of this new technique. Figure $1 \mathrm{~b}$ shows the experimental setup of the SALVI E-cell. The $\mathrm{CeO}_{2}$-containing E-cells were tested using $\mathrm{CV}$ sweeping from $-1 \mathrm{~V}$ to $1 \mathrm{~V}$ and $1 \mathrm{~V}$ to $-1 \mathrm{~V}$ at several scan rates (i.e., $10,20,40,60,80$, and $100 \mathrm{mV} / \mathrm{s}$ ), respectively. CV scans on the Nafion control SALVI E-cells were also performed to compare with those obtained from the devices with $\mathrm{CeO}_{2}$-particle WEs. The WE chips were retrieved for surface characterization using ToF-SIMS, AFM, and SEM-FIB. In comparison, the pristine, as-made WE chips containing $\mathrm{CeO}_{2}$ were characterized to determine the corrosion effects after CV sweeping.

\subsection{AFM Characterization}

A topographical analysis of the as-made and corroded WE surfaces was performed using an MFP-3D Infinity AFM (Asylum, Oxford, Santa Barbara, CA, USA). Tapping mode measurements were performed using an etched silicon probe (Bruker, RTESPA-300, $8 \mathrm{~nm}$ nominal tip radius, $40 \mathrm{~N} / \mathrm{m}$ spring constant, Billerica, MA, USA) with a set point of $3 \mathrm{~V}$ and a scan speed of $0.3 \mathrm{~Hz}$.

\subsection{ToF-SIMS Characterization}

A surface analysis of the as-fabricated WE surfaces was performed using a ToF-SIMS (IONTOF GmbH, ToF-SIMS V, Münster, Germany). The pressure of the main chamber was maintained at $1 \times 10^{-8}$ mbar during the analysis. The primary ion beam was a $25 \mathrm{keV} \mathrm{Bi}_{3}{ }^{+}$with $10 \mathrm{kHz}$ pulse energy. The pulse width was $0.8 \mathrm{~ns}$ and the current was $\sim 0.6 \mathrm{pA}$. ToF-SIMS high resolution spectral data were acquired by rastering over an area of $500 \times 500 \mu^{2}$ for 60 scans. The ToF-SIMS data were processed using the IONTOF Surface Lab 7.0 software. The mass spectra were calibrated using peaks such as $\mathrm{C}\left(\mathrm{m} / \mathrm{z}^{+} 12.0\right), \mathrm{CH}_{3}$ $\left(\mathrm{m} / \mathrm{z}^{+} 15.02\right)$, and $\mathrm{Ce}^{+}\left(\mathrm{m} / \mathrm{z}^{+} 139.90\right)$ in the positive ion mode.

\subsection{SEM-FIB}

The SEM-FIB liftout samples were prepared using a FEI, Helios 660 (Thermo Fisher, Waltham, MA, USA). The lift-out specimens were obtained by milling out an interfacial sample of the $\mathrm{CeO}_{2}$ from the device. Milling was performed under the ion-beam source at $30 \mathrm{kV}$ and $0.79 \mathrm{nA}$. The voltage was reduced to $5 \mathrm{kV}$ for the final thinning of the crosssection. Electron micrographs of the pristine and corroded $\mathrm{CeO}_{2}$ electrodes were acquired using a secondary electron detector at $5 \mathrm{kV}$ and $3.2 \mathrm{nA}$ current.

\subsection{XPS}

The XPS measurements were performed with a Thermo Fisher NEXSA (Waltham, MA, USA). This system uses a focused monochromatic Al K $\alpha(1468.7 \mathrm{eV})$ source for excitation with a double-focusing hemispherical analyzer with multi-element input lens and 128 channel detector. The X-ray beam is incident to normal to the sample and the 
photoelectron detector is $60^{\circ}$ off normal. High-energy resolution spectra were collected using a pass-energy of $50 \mathrm{eV}$ with a step size of $0.1 \mathrm{eV}$ and a dwell time of $50 \mathrm{~ms}$. The full-width-at-half-maximum (FWHM) was measured to be $0.82 \mathrm{eV}$ for the $\mathrm{Cu}\left(2 \mathrm{p}_{3 / 2}\right)$ peak using the same conditions as those at which the narrow scan spectra were collected.

The XPS Ce(3d) narrow scan region was deconvoluted using the $3 d_{5 / 2}$ peaks in Casa XPS (v 2.3.24) with a GL (80) peak shape. The $3 d_{3 / 2}$ peaks were not needed for analysis since they featured a fixed area ratio (2:3) and spin orbit coupling distances $(18.10 \mathrm{eV})$. The charge referencing was performed using the most intense Ce $3 \mathrm{~d}_{5 / 2}$ peak at $916.7 \mathrm{eV}$ [25]. Additional fitting information can be found in the supporting experimental details in the section on supplemental information.

\section{Results and Discussion}

\subsection{WE Fabrication Optimization}

Two different Nafion concentrations ( $5 \mathrm{wt} \%$ and $20 \mathrm{wt} \%$ ) of $10 \mu \mathrm{L}$ droplets and three spinning speeds (i.e., 0, $500 \mathrm{rpm}, 1000 \mathrm{rpm}$ ) were tested to reach an optimal result. When using different spinning rates, the Nafion membrane thickness varies. Table 1 presents a summary of the Nafion membrane thickness corresponding to the spinning rates. The fabricated Nafion layer using the optimized conditions is approximately $150 \mathrm{~nm}$ thick. After applying the series conditions to develop the Nafion coating on top of the target particles, an optimized condition was determined, that is, one drop of $10 \mu \mathrm{L}$ of $5 \mathrm{wt} \%$ Nafion solution spin-coated at $1000 \mathrm{rpm}$. This device performance was verified by comparing the electrochemical analysis results of different devices prepared using the listed conditions in duplicates in Table 1.

Table 1. Nafion membrane fabrication conditions for thickness optimization.

\begin{tabular}{ccccccc}
\hline No. & Nafion (\%) & $\begin{array}{c}\text { Spin Rate } \\
(\mathbf{r p m})\end{array}$ & $\begin{array}{c}\text { Curing Time } \\
(\mathbf{m i n})\end{array}$ & $\begin{array}{c}\text { Footprint } \\
\left(\mathbf{m m} \times \mathbf{m m}^{\mathbf{2}}\right)\end{array}$ & $\begin{array}{c}\text { Avg. Thickness } \\
(\boldsymbol{\mu m})\end{array}$ & Note \\
\hline 1 & 5 & 500 & 30 & $2.1 \times 2.2$ & 0.13 & Nafion only \\
2 & 5 & 1000 & 30 & $2.1 \times 2.1$ & 0.12 & Nafion only \\
3 & 20 & 500 & 30 & $2.4 \times 1.7$ & 1.18 & Nafion only \\
4 & 20 & 1000 & 30 & $2.0 \times 2.1$ & 0.83 & Nafion only \\
5 & 20 & 500 & 30 & $2.5 \times 2.4$ & 14.21 & Nafion over CeO $_{2}$ deposit \\
6 & 20 & 1000 & 30 & $1.8 \times 1.8$ & 6.45 & Nafion over CeO $_{2}$ deposit \\
\hline
\end{tabular}

Higher spinning rates result in thinner membranes and potentially better electrochemical results in the test cases evaluated in this work. The comparisons in Figure S2d-f show distinct features of $\mathrm{CV}$ profiles such as peaks $0.3 \mathrm{~V}$ (from $-1 \mathrm{~V}$ to $1 \mathrm{~V}$ ) and $0.7 \mathrm{~V}$ (from $1 \mathrm{~V}$ to $-1 \mathrm{~V}$ ) from the Nafion control (Figure 2d). It is interesting that major peaks in Figure S2d shift to the left by $\sim 0.1 \mathrm{~V}$, corresponding to the thinnest Nafion membrane in the $20 \mathrm{wt} \%$ Nafion batches of devices. This result indicates that the Nafion background in the $\mathrm{CV}$ profile becomes subservient as its layer getting thinner. Therefore, the optimal Nafion spin coating procedure would be a $1000 \mathrm{rpm}$ spin using the $5 \mathrm{wt} \%$ Nafion solution. Additionally, increasing the target particle amount could increase the signal intensities to capture unique characteristics as well. An example is given in Figure S3.

To achieve optimal conditions, we chose to increase the particle mass loading by 10 times and to decrease the Nafion layer thickness, that is, increasing the $\mathrm{CeO}_{2}$ to $6 \mathrm{mg}$ and using the thinnest Nafion from $5 \mathrm{wt} \%$ Nafion with a $1000 \mathrm{rpm}$ spinning rate. Devices fabricated using this method show a significant improvement compared to those made using the conductive silver epoxy as the binder material, as described in our recent publication [16].

Using optimized conditions, the $\mathrm{CeO}_{2}$ device $\mathrm{CV}$ profile (Figure $\mathrm{S} 3 \mathrm{a}, \mathrm{b}$ ) results show that using the Nafion binder causes less interference and improves particle deposition in a more controlled manner. During potential sweeps of the oxidation process of the $\mathrm{CeO}_{2}$, the anodic peaks were observed at potentials $\left(\mathrm{E}_{\mathrm{pa}}\right)$ of $-0.75 \mathrm{~V}$ and $0.022 \mathrm{~V}$. In comparison, the 
Nafion control device's CV profiles show two peaks at $-0.596 \mathrm{~V}$ and $0.239 \mathrm{~V}$, respectively. Similarly, during the reduction process of the $\mathrm{CeO}_{2}$, the observed cathodic peak potentials were $\left(\mathrm{E}_{\mathrm{pc}}\right)$ of $0.446 \mathrm{~V}$ and $-0.134 \mathrm{~V}$, respectively. By contrast, the Nafion control device $\mathrm{CV}$ profiles were $0.647 \mathrm{~V}, 0.056 \mathrm{~V}$, and $-0.476 \mathrm{~V}$, respectively. We also plotted current vs. square root of scan rates to show linear trend relations in Figure S3c. This finding of the $\mathrm{CeO}_{2}$-loaded E-cell demonstrates the good reproducibility of the devices using the newly developed Nafion fabrication method.

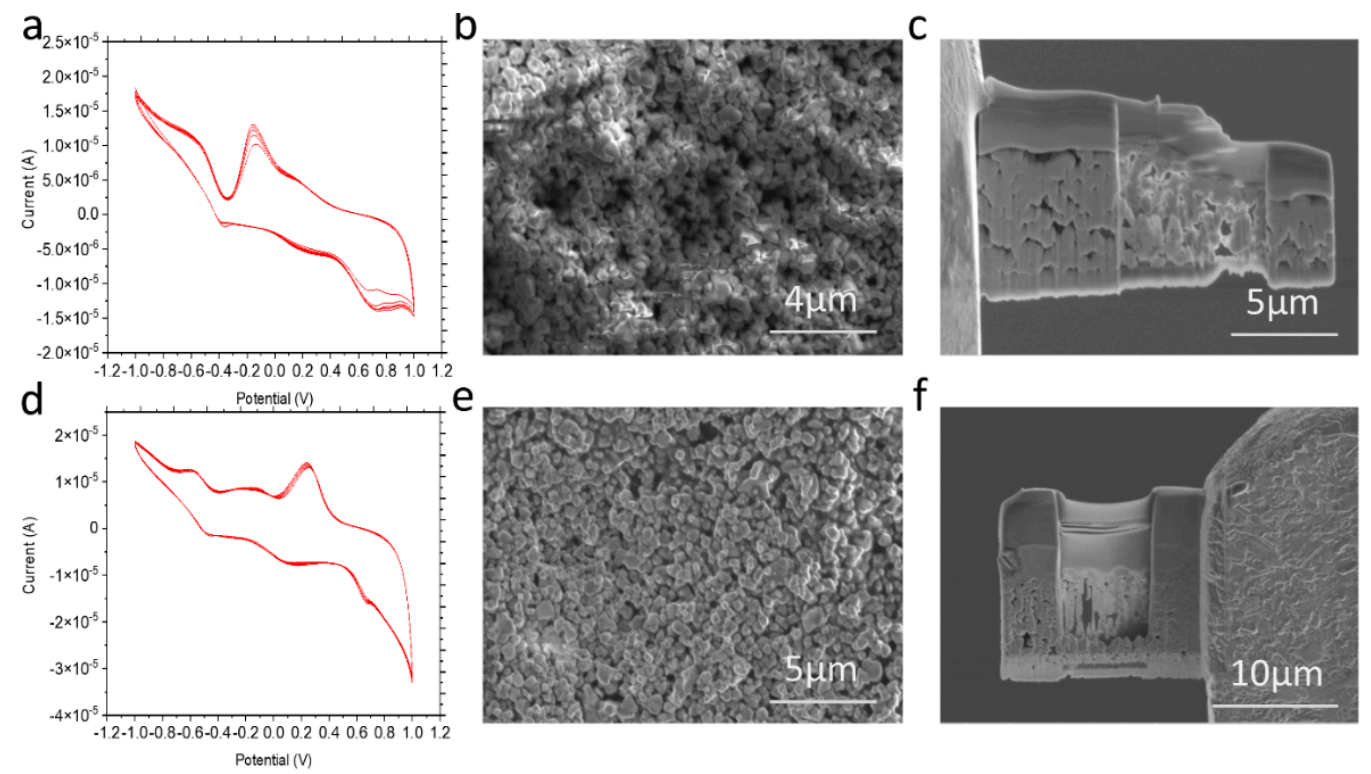

Figure 2. (a) $\mathrm{CV}$ results of $\mathrm{CeO}_{2}$-applied electrochemical cell using $5 \%$ Nafion, $1000 \mathrm{rpm}$ spin rate and $80 \mathrm{mV} / \mathrm{s}$ scan rate, (b) SEM image of the $\mathrm{CeO}_{2}$ WE surface after electrochemical corrosion with a magnification of 14,000 X, (c) SEM-FIB image of the suspended lamella from the corroded $\mathrm{CeO}_{2}$ WE surface with a magnification of $12,000 \mathrm{X}$, (d) CV results of the Nafion only control using $5 \mathrm{wt} \%$ Nafion $500 \mathrm{rpm}$ spin rate and $80 \mathrm{mV} / \mathrm{s}$ scan rate, (e) SEM image of the pristine $\mathrm{CeO}_{2}$ WE surface with a magnification of 12,000, and (f) SEM-FIB image of the suspended lamella from the pristine $\mathrm{CeO}_{2}$ WE surface with a magnification of 6500 .

\subsection{SEM-FIB Characterization}

FIB-SEM was used to obtain images of the surface of $\mathrm{CeO}_{2}$ WE. Figure $2 b$ shows the morphology of the $\mathrm{CeO}_{2} \mathrm{WE}$ after 100 cycles of $\mathrm{CV}$ scanning. Corrosion makes the surface relatively rougher compared to the pristine $\mathrm{CeO}_{2}$ surface (Figure 2e). This observation can be explained by the possible redistribution of Nafion as a result of CV sweeping $[17,26]$. Figure $2 \mathrm{c}$ also shows a slight Nafion layer thickness reduction compared to Figure $2 \mathrm{f}$, as indicated by the white marks. Additional SEM-FIB trench images are presented in Figure S4.

\subsection{ToF-SIMS Spectral Analysis and 2D Mapping}

The ToF-SIMS molecular mapping of the $\mathrm{CeO}_{2}$ particles as the WE in the SALVI E-cells and nanometer resolution AFM imaging of the electrode surface topography before (RMS: $140 \mathrm{~nm}$ ) and after running CV (RMS: $428 \mathrm{~nm}$ ) are depicted in Figure 3. Boththe ToF-SIMS and the AFM imaging results show that an even Nafion layer was deposited on top of the $\mathrm{CeO}_{2}$ particles before applying potential sweeps. The $\mathrm{Ce}^{+}$and $\mathrm{CeO}^{+}$signal intensities are lower in the pristine electrode surface (Figure $3 \mathrm{a}, \mathrm{b}$ ) compared to those after running $\mathrm{CV}$ (Figure $3 \mathrm{~g}, \mathrm{~h}$ ). This is because the $\mathrm{CeO}_{2}$ was covered by the Nafion layer. In contrast, the Nafion fragment ions (e.g., $\mathrm{C}_{4} \mathrm{~F}_{5}{ }^{+}, \mathrm{C}_{4} \mathrm{~F}_{7}{ }^{+}$) show much higher ion intensities in the as-prepared electrode surface (Figure 3c,d) compared to after its use in the electrochemical experiments (Figure 3i,j). After performing electrochemical corrosion, higher $\mathrm{Ce}^{+}$and $\mathrm{CeO}^{+}$ signals are observed (Figure 3g,h). More similar observations are reported in Figure S5. The 
AFM results show that an even Nafion film (Figure 3e,f) is formed using the spin coating technique. Both ToF-SIMS and AFM observations indicate that the Nafion membrane provides a safe protection layer with $\mathrm{CeO}_{2}$ particles as the WE. Once it had been used in the CV experiments, the Nafion was redistributed due to proton transfer (Figure 3i,k), exposing the $\mathrm{CeO}_{2}$ particles to the electrolyte. It is worth noting that one hundred cycles of potential sweeps were performed using the WE inside a SALVI cell before the ToF-SIMS and AFM surface mapping. Our results show that the devices prepared using the novel Nafion and particle attachment method can be used for extensive electrochemical testing.

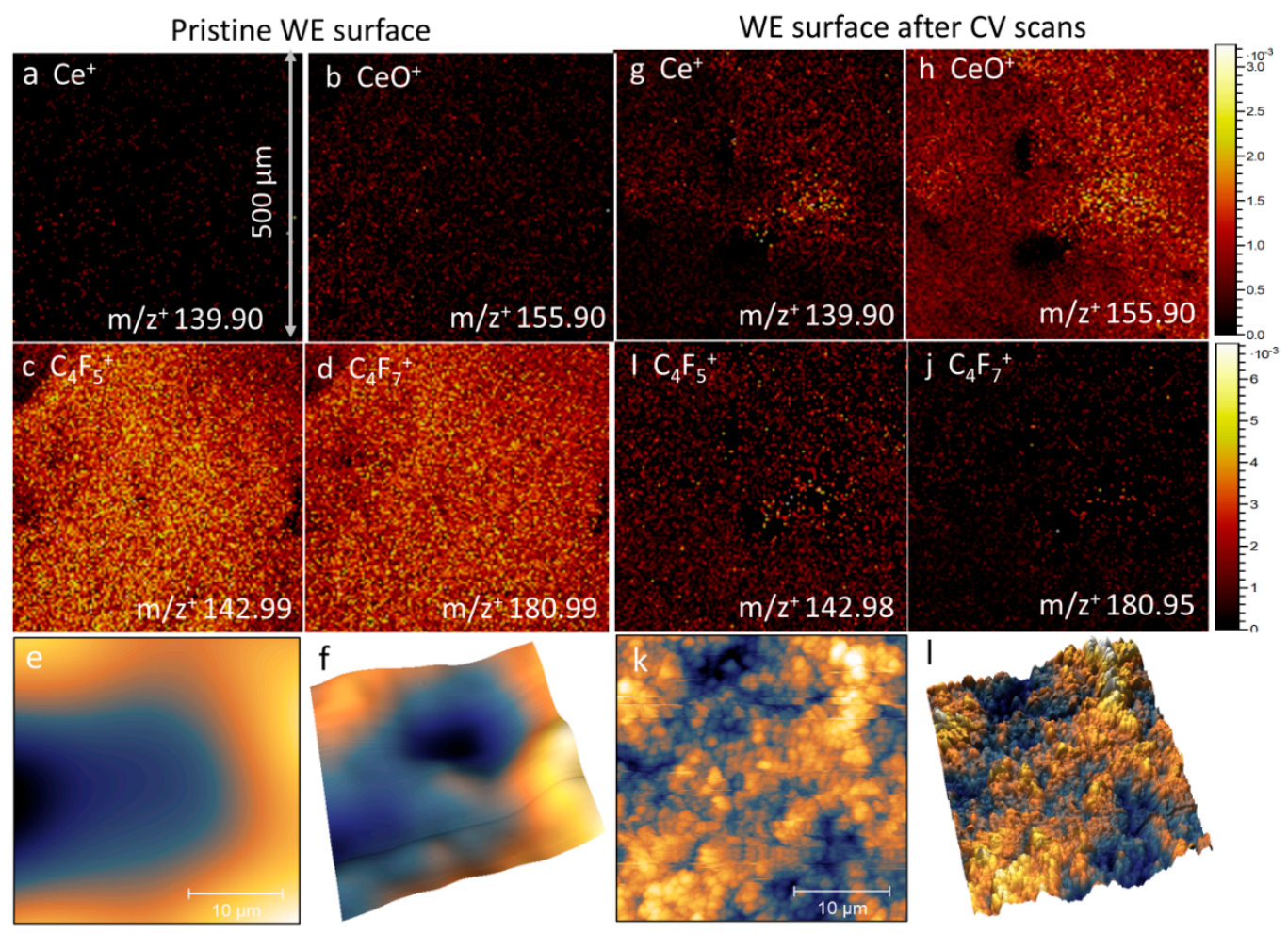

Figure 3. Normalized ToF-SIMS 2D positive ion images of representative $\mathrm{CeO}_{2}$ particles and Nafion fragments on a pristine $\mathrm{CeO}_{2} \mathrm{WE}$ surface: (a) $\mathrm{Ce}^{+}$, (b) $\mathrm{CeO}^{+}$, (c) $\mathrm{C}_{4} \mathrm{~F}_{5}{ }^{+}$, and (d) $\mathrm{C}_{4} \mathrm{~F}_{7}{ }^{+}$. Corresponding AFM images of the as-fabricated electrode (e) 2D surface and (f) 3D amplitude images. Similarly, representative ToF-SIMS $2 \mathrm{D}$ positive ion images of the $\mathrm{CeO}_{2} \mathrm{WE}$ surface after $\mathrm{CV}$ scans depicted in $(\mathbf{g}-\mathbf{j})$ and AFM 2D/3D images $(\mathbf{k}, \mathbf{l})$, respectively.

Figure 4 depicts the positive ToF-SIMS spectra of the corroded and pristine $\mathrm{CeO}_{2} \mathrm{WE}$ surface. The spectral results corroborate with the 2D mapping. Much stronger Nafion fragment peaks, such as $\mathrm{C}_{4} \mathrm{~F}_{5}{ }^{+} \mathrm{m} / \mathrm{z}^{+} 142.99$ (Figure $4 \mathrm{a}$ ) and $\mathrm{C}_{4} \mathrm{~F}_{7}{ }^{+} \mathrm{m} / \mathrm{z}^{+} 180.99$ (Figure $4 \mathrm{c}$ ), are prominent on the pristine electrode surface. The peaks representing $\mathrm{CeO}_{2}$ particles, such as $\mathrm{Ce}^{+} \mathrm{m} / \mathrm{z}^{+} 139.90$ (Figure 4a) and $\mathrm{CeO}^{+} \mathrm{m} / \mathrm{z}^{+} 155.90$ (Figure $4 \mathrm{~b}$ ), are also observable in the pristine surface. However, their counts increased after potential sweeping and corrosion develops on the electrode surface, as seen in Figure $4 \mathrm{~d}, \mathrm{e}$, respectively. by contrast, the Nafion fragment peaks $\mathrm{C}_{4} \mathrm{~F}_{5}{ }^{+} \mathrm{m} / \mathrm{z}^{+} 142.98$ (Figure $4 \mathrm{~d}$ ), and $\mathrm{C}_{4} \mathrm{~F}_{7}{ }^{+} \mathrm{m} / \mathrm{z}^{+} 180.99$ (Figure $4 \mathrm{f}$ ) reduced after corrosion occurred, providing additional evidence that the Nafion redistributes. This phenomenon is not surprising, and it has been reported in the past [17,19]. It is worth noting that the possible sulfur and fluorine contamination on the WE surface was studied using ToF-SIMS spectral analysis. The SIMS spectral results provide no evidence of sulfur or fluorine interference, as shown in Figures S5 and S6 [27,28]. 

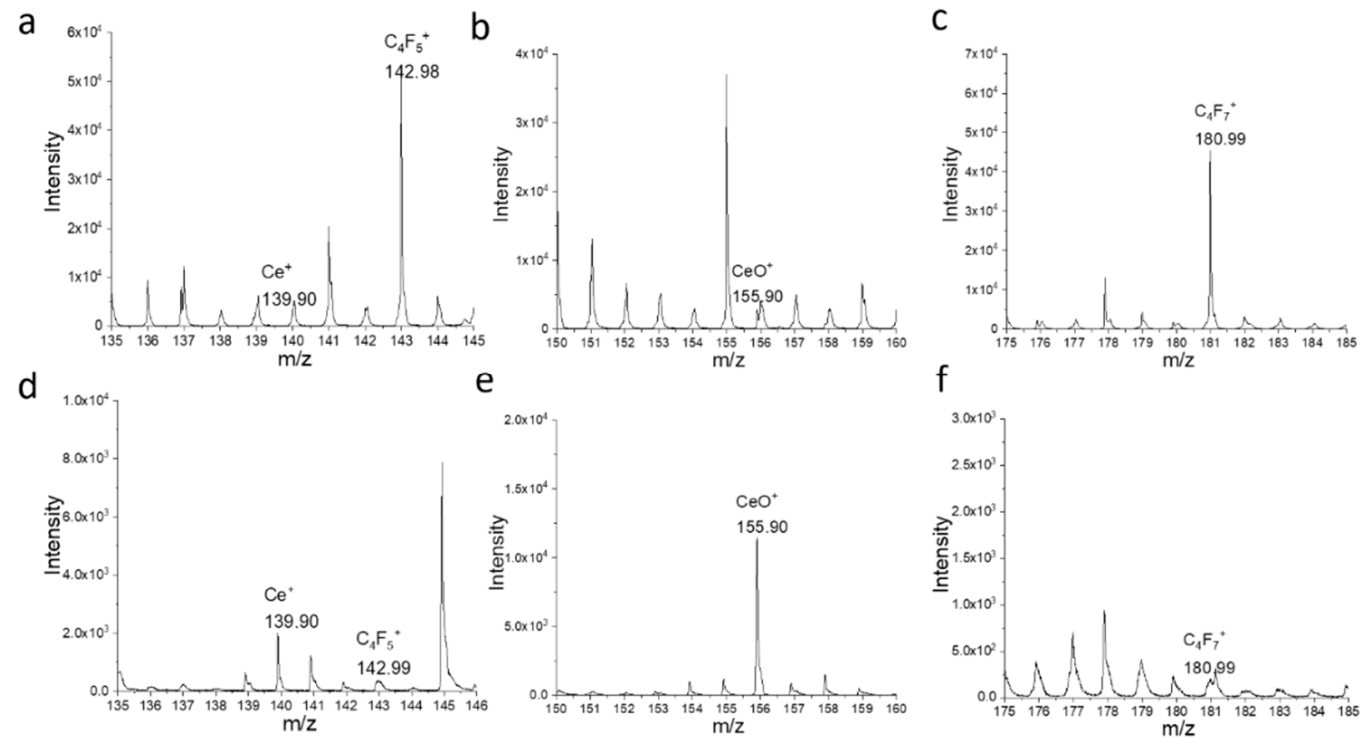

Figure 4. ToF-SIMS spectral comparison of $(\mathbf{a}-\mathbf{c})$ the pristine and $(\mathbf{d}-\mathbf{f}) \mathrm{CV}$ scanned $\mathrm{CeO}_{2} \mathrm{WE}$ surface. $\mathrm{Ce}^{+}$and $\mathrm{CeO}^{+}$peaks are related to $\mathrm{CeO}_{2}$ while $\mathrm{C}_{4} \mathrm{~F}_{7}{ }^{+}$is related to the Nafion membrane.

\subsection{XPS Analysis}

XPS narrow scan regions were used to determine the oxidation states of the pristine $\mathrm{CeO}_{2}$ WE (Figure $5 b$ ) and post-CV WE (Figure 5a). Wide scan regions are also shown in Figure $\mathrm{S} 7$. The Ce $\left(3 \mathrm{~d}_{5 / 2}\right)$ was deconvoluted to distinguish the oxidation states present. After CV (Figure 5a), the $\mathrm{Ce}^{4+}$ oxidation state was dominant, which indicates that electrochemical oxidation of the $\mathrm{Ce}^{3+}$ to $\mathrm{Ce}^{4+}$ occurred as a result of the $\mathrm{CV}$ scan. This $\mathrm{Ce}^{4+}$ oxidation state was also confirmed by the increase in the intensity of $916.7 \mathrm{eV}$ and the disappearance of shoulders present in the pristine electrode shown in Figure S8. Two oxidation states can be observed in the pristine $\mathrm{CeO}_{2} \mathrm{WE}$ case, which was dominated by $\mathrm{Ce}^{4+}$. This was likely due to air oxidation during storage $[29,30]$. The calculated ratio between $\mathrm{Ce}^{3+}$ and $\mathrm{Ce}^{4+}$ in the pristine WE case are $29.7 \%$ and $70.3 \%$, respectively.

a

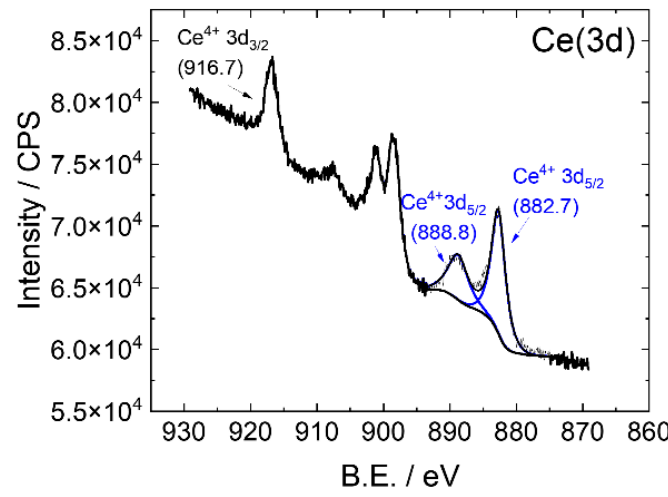

b

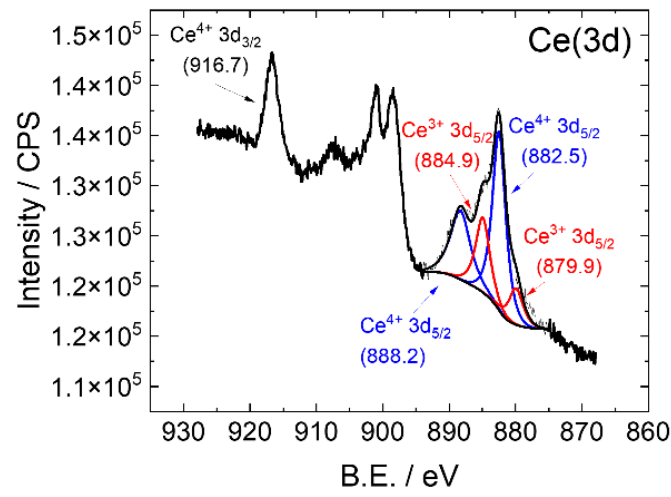

Figure 5. XPS narrow scan regions of the $\mathrm{Ce}(3 \mathrm{~d})$ after $\mathrm{CV}(\mathbf{a})$ and pristine WE condition (b).

Further evidence of $\mathrm{Ce}^{3+}$ is shown in Figure $\mathrm{S} 8$ by the presence of shoulders and a lower intensity peak at $916.7 \mathrm{eV}$ relative to after electrochemical cycling or fully oxidized state [25]. The peak positions and intensity ratios (Tables S1 and S2) also resemble the results reported by Paparazzo et al. [25]. The conversion of the $\mathrm{Ce}^{3+}$ oxidation state to $\mathrm{Ce}^{4+}$ after electrochemical cycling indicates the redox activity of the cerium particles on the electrode surface. Thus, the XPS results further confirm that Nafion-assisted $\mathrm{CeO}_{2}$ particle deposition as WE is viable. 
Direct deposition on an electrode (DDE) is a widely used approach to making electrodes. In fact, powders have been applied using DDE. However, controlling the amount of material dispensed onto a surface is difficult in DDE [31,32]. The new Nafion and particle attachment method provides a better solution compared to DDE. More importantly, the new development presented here allows flexible electrode preparation using different kinds of particles that are compatible with the microfluidics platform. $\mathrm{CeO}_{2}$ is an important material for energy applications $[33,34]$. The development of this DDE WE to be used in microfluidic cells can provide a multimodal platform for rapid electrochemical testing, for example, in studying rare earth materials [35]. In this study, we used $\mathrm{CeO}_{2}$ as an analogue to establish the protocol for studying uranium oxide corrosion in the future [4]. It is anticipated that the developed approach will be adapted to study other, more challenging materials, such as $\mathrm{UO}_{2}$.

\section{Conclusions}

$\mathrm{CeO}_{2}$ was used as a surrogate of spent fuel $\mathrm{UO}_{2}$ particles to develop a new method to fabricate effective WE in the SALVI electrochemical cell. A layer of thin Nafion membrane was developed via spin coating to protect the target particles. This new method provides a valuable electrochemical analysis tool for studying materials and understanding their corrosion potentials in the future. The fabrication workflow was optimized. The effects of Nafion weight percentages and spinning rates on the Nafion membrane thickness were investigated. Multiple devices were prepared using varying parameters. Their electrochemical performance was evaluated using CV. Our results show that the device-todevice reproducibility is reliable. More importantly, the electrochemical characteristics in the $\mathrm{CeO}_{2}$-containing devices feature distinguished redox potentials that differ significantly from those of the Nafion controls. It is expected that this new solution will be used to study spent fuel redox chemistry, since it will offer a diverse platform to introduce syn fuels, noble metal particles, or controlled dopants as WEs. More systematic studies will be performed using microfluidics to study the spent fuel chemistry at the material interfaces in the future.

Supplementary Materials: The following are available online at https://www.mdpi.com/article/ 10.3390/mi12111414/s1. Figure S1: (a) the optical microscopy image of the as-made $\mathrm{CeO}_{2} \mathrm{Nafion}$ working electrode (WE) and (b) the profilometer measurement image of the $\mathrm{CeO}_{2} \mathrm{Nafion} W E$. Figure S2: the $\mathrm{CeO}_{2} \mathrm{WE} C \mathrm{~V}$ plots with different Nafion fabrication conditions-(a) $\mathrm{CeO}_{2} \mathrm{WE} 5 \mathrm{wt} \%$ Nafion with $1000 \mathrm{rpm}$ spin rate, (b) $\mathrm{CeO}_{2} \mathrm{WE} 5 \mathrm{wt} \%$ Nafion with $500 \mathrm{rpm}$ spin rate, (c) $\mathrm{CeO}_{2} \mathrm{WE}$ $5 \mathrm{wt} \%$ Nafion with drop application, (d) $\mathrm{CeO}_{2}$ WE $20 \mathrm{wt} \%$ Nafion with $1000 \mathrm{rpm}$ spin rate, (e) $\mathrm{CeO}_{2}$ WE $20 \mathrm{wt} \%$ Nafion with $500 \mathrm{rpm}$ spin rate, and (f) $\mathrm{CeO}_{2}$ WE $20 \mathrm{wt} \%$ Nafion with drop application. The scanning rate is at $100 \mathrm{mV} / \mathrm{s}$. Figure S3: reproducibility of optimized $\mathrm{CeO}_{2}$ devices using (a) $100 \mathrm{mV} / \mathrm{s}$ scan rate, (b) $80 \mathrm{mV} / \mathrm{s}$ scan rate, and (c) the current vs. square root of scan rate plot. Ipa refers to oxidation peak current and Ipc reduction peak current. Figure S4: SEM FIB images of (a) the trench of the $\mathrm{CeO}_{2} \mathrm{WE}$ after electrochemical corrosion and (b) the pristine $\mathrm{CeO}_{2} \mathrm{WE}$, using 6500 times magnification. Figure S5: ToF-SIMS spectral results in (a) the corroded $\mathrm{CeO}_{2} \mathrm{WE}$ after electrochemical corrosion and (b) the pristine $\mathrm{CeO}_{2} \mathrm{WE}$ in the mass range of $\mathrm{m} / \mathrm{z}^{+} 1-355$. Figure S6: ToF-SIMS spectral results of (a) the corroded $\mathrm{CeO}_{2} \mathrm{WE}$ after electrochemical corrosion and (b) the pristine $\mathrm{CeO}_{2}$ WE in the mass range of $\mathrm{m} / \mathrm{z}^{+} 1-355$. Figure S7: XPS wide scan spectral results of (a) the corroded $\mathrm{CeO}_{2} \mathrm{WE}$ after electrochemical corrosion, (b) the pristine $\mathrm{CeO}_{2} \mathrm{WE}$, and (c) the Nafion membrane. Figure S8: Normalized $\mathrm{Ce}(3 \mathrm{~d})$ spectra before and after cyclic voltammetry. Regions indicative of $\mathrm{Ce}^{3+}$ are marked (1), (2), and (3), respectively. Table S1: XPS peak positions and corresponding FWHM values for the electrode analyzed before CV. Table S2: XPS peak positions and corresponding FWHM values for the electrode analyzed after $\mathrm{CV}$. 
Author Contributions: J.S. developed the methods and performed the experimental work presented in this paper. He also performed the ToF-SIMS analysis. He wrote and revised the manuscript with X.-Y.Y. E.C.B. contributed to project technical direction and administration support as the project manager. He also provided discussion direction of the manuscript. S.L.R. performed the AFM analysis. He also contributed to the initial draft of AFM methodology and data analysis. S.T. performed the SEM/FIB analysis and contributed to the initial draft of SEM/FIB methodology. M.H.E. and L.E.S. performed the XPS analysis and contributed initial draft of the XPS methodology and data analysis. All the authors revised the paper. X.-Y.Y. developed the method and supervised the experiments. She wrote and revised the manuscript with J.S. All authors have read and agreed to the published version of the manuscript.

Funding: The programmatic support for this work was from the U.S. Department of Energy Nuclear Energy Spent Fuel Waste Science Technology (SFWST) program (Project\# 60410). X.-Y.Y. thanks the Office of Science, Office of Basic Energy Sciences, of the U.S. DOE through the Direct Air Capture Program for partial support for the electrode development and characterization. Part of the work was performed using the Environmental Molecular Sciences Laboratory (grid436923.9), a DOE Office of Science User Facility sponsored by the Office of Biological and Environmental Research. PNNL is operated by Battelle under the contract DE-AC05-76RL01830.

Data Availability Statement: Data is contained within the article or supplementary material.

Conflicts of Interest: The authors declare no conflict of interest. The funders had no role in the design of the study; in the collection, analyses, or interpretation of data; in the writing of the manuscript, or in the decision to publish the results.

\section{References}

1. Cureton, W.F.; Tracy, C.L.; Lang, M. Review of Swift Heavy Ion Irradiation Effects in $\mathrm{CeO}_{2}$. Quantum Beam Sci. $2021,5,19$. [CrossRef]

2. García-Ostos, C.; Rodríguez-Ortiz, J.A.; Arévalo, C.; Cobos, J.; Gotor, F.J.; Torres, Y. Fabrication and characterization of CeO 2 pellets for simulation of nuclear fuel. Nucl. Eng. Des. 2016, 298, 160-167. [CrossRef]

3. Torres, Y.; García-Ostos, C.; Arévalo, C.; Gotor, F.J.; Pavón, J.J.; Trueba, P.; Rodríguez-Ortiz, J.A. Processing and characterization of surrogate nuclear materials with controlled radial porosity. J. Nucl. Sci. Technol. 2017, 54, 167-173. [CrossRef]

4. Fernandez, S.; Nieto, M.I.; Cobos, J.; Moreno, R. $\mathrm{CeO}_{2}$ pellet fabrication as spent fuel matrix analogue. J. Eur. Ceram. Soc. 2016, 36, 3505-3512. [CrossRef]

5. Nelson, A.T.; Rittman, D.R.; White, J.T.; Dunwoody, J.T.; Kato, M.; McClellan, K.J. An Evaluation of the Thermophysical Properties of Stoichiometric $\mathrm{CeO}_{2}$ in Comparison to $\mathrm{UO}_{2}$ and $\mathrm{PuO}_{2}$. J. Am. Ceram. Soc. 2014, 97, 3652-3659. [CrossRef]

6. $\quad$ Einstein, A.J.; Pascual, T.N.; Mercuri, M.; Karthikeyan, G.; Vitola, J.V.; Mahmarian, J.J.; Better, N.; Bouyoucef, S.E.; Hee-Seung Bom, H.; Lele, V.; et al. Current worldwide nuclear cardiology practices and radiation exposure: Results from the 65 country IAEA Nuclear Cardiology Protocols Cross-Sectional Study (INCAPS). Eur. Heart J. 2015, 36, 1689-1696. [CrossRef]

7. Sunder, S.; Miller, N.H.; Shoesmith, D.W. Corrosion of uranium dioxide in hydrogen peroxide solutions. Corros. Sci. 2004, 46, 1095-1111. [CrossRef]

8. Shoesmith, D.W.; Sunder, S.; Bailey, M.G.; Wallace, G.J. The Corrosion of Nuclear Fuel $\left(\mathrm{UO}_{2}\right)$ In Oxygenated Solutions. Corros. Sci. 1989, 29, 1115-1128. [CrossRef]

9. Christensen, H.; Sunder, S.; Shoesmith, D.W. Oxidation of unclear fuel $\left(\mathrm{UO}_{2}\right)$ by the products of water radiolysis: Development of a kinetic model. J. Alloy. Compd. 1994, 213, 93-99. [CrossRef]

10. Sunder, S.; Strandlund, L.K.; Shoesmith, D.W. Anodic oxidation and dissolution of CANDU fuel $\left(\mathrm{UO}_{2}\right)$ in slightly alkaline sodium perchlorate solutions. Electrochim. Acta 1998, 43, 2359-2372. [CrossRef]

11. Wang, Z.; Zhang, Y.; Liu, B.; Wu, K.; Thevuthasan, S.; Baer, D.R.; Zhu, Z.; Yu, X.Y.; Wang, F. In Situ Mass Spectrometric Monitoring of the Dynamic Electrochemical Process at the Electrode-Electrolyte Interface: A SIMS Approach. Anal. Chem. 2017, 89, 960-965. [CrossRef]

12. Yang, L.; Yu, X.Y.; Zhu, Z.; Iedema, M.J.; Cowin, J.P. Probing liquid surfaces under vacuum using SEM and ToF-SIMS. Lab Chip 2011, 11, 2481-2484. [CrossRef]

13. Yang, L.; Yu, X.-Y.; Zhu, Z.; Thevuthasan, T.; Cowin, J.P. Making a hybrid microfluidic platform compatible forin situimaging by vacuum-based techniques. J. Vac. Sci. Technol. A Vac. Surf. Films 2011, 29. [CrossRef]

14. International Atomic Energy Agency. Industerial Safety Safety Guidelines for Nuclear Facilities; IAEA Nuclear Energy Series NP-T-3.3; International Atomic Energy Agency: Vienna, Austria, 2018; p. 264.

15. Canadian Nuclear Safety Commission. Radiobioassy Protocols for Responding to Abnormal Intakes of Radionuclides; G-147; Canadian NuclearSafety Commission: Ottawa, ON, Canada, 2003; p. 27.

16. Son, J.; Buck, E.C.; Riechers, S.L.; Yu, X.Y. Stamping Nanoparticles onto the Electrode for Rapid Electrochemical Analysis in Microfluidics. Micromachines 2021, 12, 60. [CrossRef] 
17. Mauritz, K.A.; Moore, R.B. State of Understanding of Nafion. Chem. Rev. 2004, 104, 4535-4586. [CrossRef] [PubMed]

18. Nagao, Y. Highly Oriented Sulfonic Acid Groups in a Nafion Thin Film on Si Substrate. J. Phys. Chem. C 2013, 117, $3294-3297$. [CrossRef]

19. Paul, D.K.; McCreery, R.; Karan, K. Proton Transport Property in Supported Nafion Nanothin Films by Electrochemical Impedance Spectroscopy. J. Electrochem. Soc. 2014, 161, F1395-F1402. [CrossRef]

20. Kaw, K.A.Y.; Palisoc, S.T.; Natividad, M.T. A morphological and cyclic voltammetric investigation of spin-coated hexaammineruthenium (III)-incorporated Nafion ${ }^{\circledR}$ thin films. Philipp. Sci. Lett. 2014, 7, 171-178.

21. Palisoc, S.; Natividad, M.; Tadios, S. Fabrication and morphological characterization of Nafion thin films spin coated on silica. $J$. Optoelectron. Adv. Mater. 2014, 16, 759.

22. Parnian, M.J.; Rowshanzamir, S.; Alipour Moghaddam, J. Investigation of physicochemical and electrochemical properties of recast Nafion nanocomposite membranes using different loading of zirconia nanoparticles for proton exchange membrane fuel cell applications. Mater. Sci. Energy Technol. 2018, 1, 146-154. [CrossRef]

23. Liu, B.; Yu, X.Y.; Zhu, Z.; Hua, X.; Yang, L.; Wang, Z. In situ chemical probing of the electrode-electrolyte interface by ToF-SIMS Lab Chip 2014, 14, 855-859. [CrossRef]

24. Yu, J.; Zhou, Y.; Hua, X.; Liu, S.; Zhu, Z.; Yu, X.Y. Capturing the transient species at the electrode-electrolyte interface by in situ dynamic molecular imaging. Chem. Commun. 2016, 52, 10952-10955. [CrossRef] [PubMed]

25. Paparazzo, E. Use and mis-use of X-ray photoemission spectroscopy Ce3d spectra of $\mathrm{Ce}_{2} \mathrm{O}_{3}$ and CeO $\mathrm{Ce}_{2}$. J. Phys. Condens. Matter 2018, 30, 343003. [CrossRef]

26. Hiesgen, R.; Aleksandrova, E.; Meichsner, G.; Wehl, I.; Roduner, E.; Friedrich, K.A. High-resolution imaging of ion conductivity of Nafion ${ }^{\circledR}$ membranes with electrochemical atomic force microscopy. Electrochim. Acta 2009, 55, 423-429. [CrossRef]

27. Guo, R.; Talma, A.G.; Datta, R.N.; Dierkes, W.K.; Noordermeer, J.W.M. Novel Surface Modification of Sulfur by Plasma Polymerization and its Application in Dissimilar Rubber-Rubber Blends. Plasma Chem. Plasma Process. 2010, 30, 679-695. [CrossRef]

28. Ferrari, S.; Ratner, B.D. ToF-SIMS quantification of albumin adsorbed on plasma-deposited fluoropolymers by partial least-squares regression. Surf. Interface Anal. 2000, 29, 837-844. [CrossRef]

29. Wheeler, D.W. Kinetics and mechanism of the oxidation of cerium in air at ambient temperature. Corros. Sci. 2016, 111, 52-60. [CrossRef]

30. Zhu, Y.; Jain, N.; Hudait, M.K.; Maurya, D.; Varghese, R.; Priya, S. X-ray photoelectron spectroscopy analysis and band offset determination of $\mathrm{CeO}_{2}$ deposited on epitaxial (100), (110), and (111)Ge. J. Vac. Sci. Technol. B 2014, 32, 011217. [CrossRef]

31. Grygar, T.; Marken, F.; Schröder, U.; Scholz, F. Electrochemical Analysis of Solids. A Review. Collect. Czechoslov. Chem. Commun. 2002, 67, 163-208. [CrossRef]

32. Ghosh, P.K.; Bard, A.J. Clay-Modified Electrodes. J. Am. Chem. Soc. 1983, 105, 5691-5693. [CrossRef]

33. Murugan, R.; Ravi, G.; Yuvakkumar, R.; Rajendran, S.; Maheswari, N.; Muralidharan, G.; Hayakawa, Y. Pure and Co doped $\mathrm{CeO}_{2}$ nanostructure electrodes with enhanced electrochemical performance for energy storage applications. Ceram. Int. 2017, 43, 10494-10501. [CrossRef]

34. Yao, J.; Wu, F.; Qiu, X.; Li, N.; Su, Y. Effect of $\mathrm{CeO}_{2}$-coating on the electrochemical performances of $\mathrm{LiFePO}_{4} / \mathrm{C}$ cathode material. Electrochim. Acta 2011, 56, 5587-5592. [CrossRef]

35. Rosalbino, F.; Angelini, E.; De Negri, S.; Saccone, A.; Delfino, S. Influence of the rare earth content on the electrochemical behaviour of Al-Mg-Er alloys. Intermetallics 2003, 11, 435-441. [CrossRef] 